\title{
JEREMY BENTHAM E A CONSTITUIÇÃO DO CONCEITO DE DIREITO NO PENSAMENTO JURÍDICO MODERNO.
}

\author{
Christian Fernandes Gomes da Rosa*
}

\begin{abstract}
SUMÁRIO:Introdução1.Vidaeobra deJeremyBenthan2. "Umaintroduçãoaosprincípios damoral e da legislação" 3. O conceito benthamiano de Direito eo pensamentojurídico modemoConclusãoBibliografia
\end{abstract}

- Resumo: O artigo tem por escopo analisar o papel de Jeremy Bentham no desenvolvimento do conceito moderno de Direito no Ocidente. Para essa tarefa, sua obra Uma introdução aos princípios da moral e da legislação será utilizada como referência de sua contribuição na mudança conceitual que se operou na teoria e filosofia do Direito no final do século 18. Assim, o Utilitarismo, como apresentado por Bentham, e sua relação com o processo de instituição e aplicação da (boa) legislação, veio a influenciar como o Direito é considerado e pensado na Sociedade Moderna.

- Palavras-chave: utilitarismo; história do direito; conceito de direito; teoria do direito moderno

- Abstract: This paper is an attempt to consider the role of Jeremy Bentham within the development of the modern concept of Law in the Western World. To accomplish this task, his book named An Introduction to the Principles of Morals and Legislation, published in 1789 , will be taken as a reference of his contribution with the conceptual change occurred in legal theory and philosophy in the late $18^{\text {th }}$ century. Thus, the Utilitarianism, as presented by Bentham, and its relation with the process of establishment and application of (good) legislation, came to influence how Law is considered and thought in the Modern Society.

- Keywords: utilitarianism; legal history; modern legal theory

\section{Introdução}

O presente estudo tem por objetivo apresentar as contribuições de Jeremy Bentham para a conformação do conceito de Direito na modernidade, estabelecendo, assim, uma perspectiva sobre a modernidade jurídica como resultado também de manifestações desse autor.

A partir das referências que proporcionam sua biografia e bibliografia, a obra Uma introdução aos princípios da moral e da legislação será utilizada como fonte principal para a análise de como Bentham consolidou certas novas perspectivas a respeito do Direito e sua relação com a Política e a Sociedade.

Para tanto, tem-se que o estudo das relações entre o pensamento benthamiano, seus predecessores e aqueles que deram continuidade a seus postulados, é importante para que se reconstrua a evolução conceitual que se verificou naquele momento histórico. Em alguma medida, essa tarefa será ensaiada.

Sem dúvidas, reconstituir os elementos no pensamento de Bentham que são efetivamente reveladores de seu papel na modernização do Direito não é algo trivial.

\footnotetext{
"O autor é Advogado, Especialista em Direito Econômico pela Escola de Direito de São Paulo da Fundação Getúlio Vargas e Mestre em Filosofia e Teoria do Direito pela Faculdade de Direito da Universidade de São Paulo.
} 
Ao contrário: a não linearidade da história do conhecimento torna a tarefa bastante árdua.

Imposta essa dificuldade, a abordagem do tema deve ser segmentada. Assim, no presente ensaio, será primeiramente delineada uma suma biográfica de Bentham, pontuando o momento de sua vida em que desenvolveu suas obras. Essa poderá ser uma referência útil para a avaliação dos argumentos apresentados pelo autor.

Em segunda etapa, o foco será na obra supracitada, momento em que se busca apresentar os postulados trazidos pelo texto, avaliando-os, e ainda desvelar sua relevância no processo de evolução do conceito moderno de Direito.

Por fim, o presente trabalho sondará os traços de teoria jurídica que, esboçados por predecessores e consolidados por Bentham a seu tempo, parecem ter recobrado força no pensamento jurídico moderno tardio.

\section{Vida e obra de Jeremy Bentham}

Bentham nasceu em 1748 e foi tido como infante prodígio, pois aos cinco anos já lia grego e latim. Filho de advogado, estudou Direito para militar na área, seguindo desejo do pai de que seguisse a mesma carreira. No entanto, seu contato com iluministas como Locke, Montesquieu, Hume, Smith e Beccaria o levou a inspirações que se possam dizer maiores.

Na primeira obra, Um fragmento sobre o governo, analisou criticamente textos de William Blackstone. Este autor é considerado relativamente conservador em razão de sua defesa do estandarte de que a sistematização do Direito é necessária para que se efetive de melhor maneira a condução do que é naturalmente certo e a vedação do que é errado (Newman, 2002: 163).

Enquanto Blackstone descreveu o Direito inglês tal qual se fez tradicionalmente, apenas reorganizando os postulados que reiteradamente tinham servido de ponto de partida para o pensamento jurídico, Bentham buscou desenvolver uma análise normativa, prescritiva, expondo como o Direito poderia ser aperfeiçoado e tornar-se mais efetivo na busca de suas finalidades (Friedrich, 1965: 113).

O debate com Blackstone, sem dúvidas, foi de suma importância na composição de suas posições. A divergência entre Bentham e Blackstone, no entanto, não era absoluta.

A racionalização do Direito, de maneiras distintas, era algo afeto a ambos autores. Enquanto Blackstone valia-se desse mote para a sistematização de normas assentadas de maneira desorganizada pela tradição inglesa, Bentham parece ter se apropriado desse fundamento em uma perspectiva tanto mais teleológica.

Ademais, ambos mantinham a defesa da liberdade do indivíduo perante o Estado como parâmetro adequado para a relação público-privada. No que se refere a isso, a disparidade que se pode notar entre as proposições dos dois autores é resultado do grau de liberdade que era imprescindível manter e quais os danos que a tradição jurídica da época poderia sofrer a fim de assegurar esse grau (Holdsworth, 1940).

Para alguns, Blackstone avançou na racionalização do Direito, atuando no 
processo de sua modemização, mas o fez de maneira inconsistente, ou então limitada. Nesse sentido, Richard Posner (1983: 16) chega a afirmar: "Blackstone compreendeu a importância das liberdades civis, mas sua análise não era sistemática."

Bentham acreditava que era preciso efetivamente reformar o Direito, racionalizando-o sob um valor que, apesar de fundar-se em uma moral, essa não é tradicionalmente nominada natural, mas uma utilitarista.

Desse modo, ele conformou a idéia de que o Direito é fruto de uma decisão, da opção por uma política e acrescenta que essa decisão deve ser inspirada no princípio da utilidade.

Esse autor utilitarista tinha por objetivo a reforma do Direito, seja o público ou privado, mas suas atenções voltaram-se - ao menos no que concerne a essa área do conhecimento - especialmente ao Direito Penal. Já nesse sentido, em 1781 publicou Teoria do castigo e das recompensas.

Viajou para Rússia para visitar um irmão em 1785, momento em que escreveu Defesa da usura, seu primeiro trabalho de cunho propriamente econômico e pelo qual demonstra sua intenção de promover a aplicação dos princípios liberais levantados por Adam Smith.

Voltou a Londres em 1788 com o anseio por participar da vida política, mas, frustado, abandonou esse ideal e se colocou a estudar a legislação. No ano seguinte, em 1789, publicou Uma introdução aos princípios da moral e da legislação, que o fez conhecido por toda Europa e também na América Latina. Essa obra, desenvolvida em um momento em que se davam por toda parte as revoluções iluministas, efetivamente estabelece um marco na história do pensamento sobre o Direito.

Bentham ainda criou um periódico, o Westminster Review, a fim de expandir o seu ideal utilitarista e ao qual se atribui papel fundamental para a construção de uma verdadeira Escola Utilitarista que se desenvolveu no pensamento, especialmente, britânico, mas que se fez refletir nas ações políticas de países da Europa continental e na América ${ }^{1}$.

Faleceu em 1832, aos 84 anos.

\section{2. "Uma introdução aos princípios da moral e da legislação"}

Apresentados sucintos elementos da vida e obra de Jeremy Bentham, passase à explicitação dos principais argumentos construídos pelo autor em seu texto que levou o nome de "Uma introdução aos princípios da moral e da legislação", obra que se faz principal referência para o presente estudo. É o que se põe à lume.

Jeremy Bentham começa a obra pela constatação de que a natureza deixou o ser humano inexoravelmente sujeito a dois senhores: a dor e o prazer.

Demonstra, então, como as ações humanas são determinadas em face das

\footnotetext{
${ }^{1} \mathrm{Kolm}$ (1996: 405 et seq) alerta para o fato de que aquilo que se denomina genericamente por Escola Utilitarista apresenta uma grande variedade de sub-linhas de pensamento que são relativamente diferenciadas entre si. É fato que possam ser ligadas, ainda que com pouca exatidão, sob uma nomenclatura comum, mas alguma cautela é necessária na afirmação de que defendam os mesmos postulados.
} 
dores e prazeres envolvidos com o ato. Ou seja, a única causa eficiente da ação é, positivamente, a busca pelo prazer, ou negativamente, a fuga da dor (Newman, 2002).

Fundado nisso, constrói o que denomina "Princípio da Utilidade", base sobre a qual é possível julgar se qualquer comportamento é reto ou errado na medida em que for promotor ou constritor de maior felicidade.

Esclarece que felicidade é qualquer sorte de prazer, vantagem, bem, reduzindo todos esses conceitos a um mesmo senso de utilidade. Essa multiplicidade semântica desenvolvida por Bentham foi um dos fatores que viabilizou a instituição de uma variedade de sub-correntes filosóficas utilitaristas.

Bentham então defende que a definição daquilo que é reto - não para o indivíduo, mas para toda a comunidade - deve tomar por base o mesmo raciocínio, levando em conta que o interesse comum é a soma dos anseios dos indivíduos que compõem o agrupamento social.

O grande desenvolvimento é a possibilidade que Bentham apresenta de que a felicidade seja calculada e, mediante essa análise, guie-se a conduta governamental. (Newman, 2002: 157).

Com esse instrumental, é possível verificar se uma decisão governamental é reta. Basta investigar se ela é capaz de oferecer maior felicidade ao maior número de pessoas que se sujeitam a ela. Desenvolve-se, assim, uma teoria utilitarista da boa legislação.

O autor passa, então, à defesa de seu mecanismo de avaliação, o Princípio da Utilidade, imputando razão distorcida a seus adversários. Faz isso ao refutar a conveniência ou coerência dos princípios alternativos ou contrários ao da utilidade.

Ao discorrer sobre o ascetismo, demonstra que é absolutamente oposto ao da utilidade e tem por reto promover a dor e diminuir o prazer. Defende que esse princípio nunca foi observado totalmente por muito tempo e especula que, "se apenas a décima parte dos habitantes da terra o praticasse com seriedade e constância, em um dia o planeta seria transformado em um inferno." (Bentham, 1979: 9)

De outro lado, discute o princípio da simpatia ou antipatia ${ }^{2}$, que funda o julgamento da ação no sentimento que sua observação promove, sendo reto o comportamento em relação ao qual haja a simpatia. Este princípio, para Bentham, é a negação de qualquer princípio, pois busca uma referência interior para a qualificação do ato, sendo de pouca valia, pois seria necessária alguma referência exterior para que o homem pudesse, com segurança, verificar a retidão de qualquer atitude.

Bentham discorre, então, acerca do uso efetivo da moral utilitarista para a avaliação de condutas, de motivos que determinam a ação humana e da disposição que os homens apresentam. Em todo momento, evita generalizações fundadas na natureza do próprio objeto avaliado e vê a importância da análise do caso para determinar a retidão de qualquer atitude, sempre verificando as conseqüências

${ }^{2}$ Esse príncipio foi apresentado por Adam Smith como adequado auto-regulador das ações individuais no mercado. É um dos poucos elementos do pensamento benthamiano que diverge do ideário de Smith, a quem Bentham costumeiramente rendia tributos. 
esperadas e efetivamente geradas.

Sumaria Bentham (1979: 40): "Face a tudo que acabamos de expor, concluise que não existe nenhuma espécie de motivo que seja má em si mesma, como tampouco existe motivo algum que seja em si mesmo exclusivamente bom."

A qualificação que se dará à ação dependerá das circunstâncias bem como da inteligência e opiniões dos avaliadores. Será sobre o seu motivo e a intenção que nasce dele, bem como de seus efeitos. A intenção é boa ou má com relação aos efeitos materiais que se esperava da mesma.

Assim, não é próprio diferir os motivos entre bons e maus, mas é possível classificá-los segundo a vantagem social que costumam gerar.

Para Bentham, são motivos sociais, tendentes a promover a maximização da felicidade social, a benevolência, o amor à reputação, o desejo de amizade e a religião.

Motivos pessoais (self-regarding) são aqueles que importam muito mais ao próprio indivíduo do que para a sociedade como um todo e são o desejo físico, o interesse pecuniário, o amor ao poder e a autopreservação.

O motivo anti-social é aquele que, via de regra conforme empiricamente verificável, tende a gerar a minimização da felicidade geral e assim é classificado o desgosto.

Bentham dispõe os motivos em razão de sua maior proximidade ao Princípio da Utilidade, iniciando-se pela benevolência e terminando pelo desgosto, explicando que, mesmo assim, a utilidade neste último pode ser até maior que o primeiro em determinadas circunstâncias.

Ao debater as características próprias de um indivíduo sobre o quanto ele costuma coadunar com o Princípio da Utilidade, Bentham volta-se ao estudo do que denomina a disposição de cada pessoa. Disposição é a qualidade que se avalia num ser de ceder mais ou menos facilmente a uma tentação ou efetivar ou não um bem.

Isso interfere no quantum da punição, que por si é um mal, mas se justifica se evita mal maior - sendo impedida quando imotivada, ineficaz, inútil, dispendiosa e supérflua. Nota-se aqui uma tentativa franca de Bentham de promover uma racionalização dos instrumentos persecutórios do Estado inglês.

Nessa esteira, a sanção deve criar o desestímulo ao crime, impondo prejuízo equivalente ao benefício do ilícito, neutralizando os ganhos esperados pelo delito e, mais, criando perdas em caso de infração a utilidades públicas (benevolência contra crueldade) e privadas (sossego ao invés da turbação).

Em sua obra, Bentham tratar ainda da distinção entre a ética e a legislação.

Define ética como "a arte de dirigir as ações do homem para a produção da maior quantidade possível de felicidade em benefício daqueles cujos interesses estão em jogo." (Bentham, 1979: 63).

Demonstra, então, que o autogoverno, a regulação dos comportamentos pelo próprio indivíduo, é a ética privada, que não é o foco de suas maiores atenções, pois essa pode levar a felicidade pessoal.

Bentham debruça-se com maior afinco sobre as questões da felicidade geral, de 
toda a sociedade. Para tanto, vê na legislação o correspondente social da ética privada.

Para ele, o governo de outras pessoas, baseado em regras, é legislação. "Na medida em que as praticas em que se manifesta a arte de governar são de natureza permanente, essa arte se denomina geralmente legislação." (Bentham, 1979: 64).

Discorre que a ética de ações que afetam outras pessoas chamam-se obrigações para com outras pessoas e no que se refere à felicidade, pode ser positiva (beneficência) ou negativa (probidade).

Mas indaga-se que, afastando a religião e a legislação, que motivos podem levar uma pessoa a querer a felicidade de outra. Sua resposta é incisiva: apenas os próprios interesses individuais que, se alinhados com os anseios sociais, fazem da busca humana pela própria felicidade em uma busca pela utilidade geral. Isso ocorre porque os motivos sociais ou semi-sociais levam a tanto. Buscando fim próprio (amizade, reputação), traz felicidade a outros.

Bentham então opera a distinção entre a ética privada e a legislação, pois apesar dos atos parecerem sempre objeto de ambos, assim não o é, pois nem tudo que a ética coíbe ou promove, a legislação deve ocupar-se.

Em geral, não deve o legislador tratar daqueles atos que ficam no campo de ação individual e que, apesar de poderem ser qualificados como certos ou errados, não afetam a sociedade. A atenção do legislador deve se voltar àquelas questões que envolvam a probidade, ou seja, de maneira a suprimir a atuação daqueles indivíduos cujos atos faz que a felicidade seja minorada.

Conclui-se nas próprias palavras de Bentham (1979: 68):

A arte da legislação - a qual pode ser considerada como um setor da ciência da jurisprudência - ensina como uma coletividade de pessoas, que integram a comunidade, pode dispor-se a empreender o caminho que, no seu conjunto, conduz com maior eficácia à felicidade da comunidade inteira, e isso através de motivos a serem aplicados pelo legislador.

Assim, quanto à legislação, Bentham frisa a sua qualificação como instrumento de política, de determinação fundada em motivos eleitos pelos legisladores e, em última análise, dispostas em nome do Estado. A própria legislação, considerada como um "setor da ciência da jurisprudência", e assim do Direito como é considerado modernamente, perde em Bentham a sua vinculação estrita com a racionalidade, natural, e passa a se fundar na própria vontade política.

\section{O conceito benthamiano de Direito e o pensamento jurídico moderno}

Mas para bem compreender a contribuição do pensamento benthamiano na constituição do pensamento jurídico moderno, é preciso ainda trazer à luz algum aumento de complexidade nos objetivos da teoria utilitária. O Utilitarismo não só propõe a defesa daquelas qualificações que, notadamente sociais, maximizam a felicidade geral, mas também a promoção daquilo que, apesar de ser em si irrelevante para a felicidade comum, é um meio adequado para que essa utilidade social seja 
alcançada (Coleman; Murphy, 1990: 74).

Logo, justamente pelo fato de que a Escola Utilitarista tem por tradição a manutenção do foco nas conseqüências dos atos e não exatamente nos meios incluindo valores - pelos quais são perpetrados, paradoxalmente o meio ganha sua importância na análise já que, por si só, também é responsável por determinar conseqüências.

É preciso esclarecer também que a moral utilitarista instituída por Bentham em nada nega a possibilidade da estruturação de normas abstratas a conduzirem o comportamento humano. Tanto pelo contrário. Ainda que a análise casuística seja defendida por Jeremy como importante na implementação do Princípio da Utilidade, é possível, sim, a definição de regras gerais que possam ser instituídas pelo Direito.

$\mathrm{O}$ instrumento que torna isso possível provém da diferenciação entre o denominado Act Utilitarism e o Rule Utilitarism. ${ }^{3}$

O primeiro promove a aplicação do Princípio da Utilidade a cada ato individual e aconselha que toda ação social deve se pautar de maneira a promover o maior grau de felicidade ao maior número de indivíduos.

O segundo, instrumento de generalização, configura-se mediante a análise das conseqüências que comumente se verificam na prática de determinados atos; se alguma conduta empiricamente verifica-se como usual geradora de felicidade, é possível então formular uma regra abstrata que a permita ou a promova. Em caso contrário, situação em que determinada classe de conduta geralmente traz conseqüências minimizadoras da felicidade agregada, será conveniente que haja norma jurídica que a obste ou proíba.

Essa evolução no próprio utilitarismo, com a constituição do Rule Utilitarianism, viabilizou que seus postulados se tomassem uma referência para a elaboração das normas jurídicas, que se pretendem abstratas. Sem isso, as soluções trazidas pelo utilitarismo - Act Utilitarianism - dependeriam da análise concreta das peculiaridades de cada um dos casos, o que tornaria impossível a sua utilização como referência para a disposição de normas jurídicas.

Bentham não só desenvolveu uma teoria moral que pudesse servir de guia para a constituição do Direito. Ele desenvolveu - ou ao menos fez prosperar - muitos conceitos ligados ao Direito que foram fundamentais para a conformação da modernidade jurídica.

Pode parecer até paradoxal que um autor que criou uma teoria bastante interessante no que se refere a uma moral a fundar o Direito, tenha sido um dos grandes responsáveis para separar o Direito de sua fundamentação tradicional e delegá-la à vontade do soberano, empiricamente constatado como tal.

Mas ao definir racionalmente sua proposta de ideal normativo - suas sugestões para o sistema jurídico - ele demonstrou que o Direito vigente não possuía

\footnotetext{
${ }^{3}$ Essa diferenciação pode ser encontrada em quase todos os autores que tratam da relação entre a filosofia utilitarista e o Direito e de fato parece ser ferramenta fundamental para que haja coerência na defesa da possibilidade de que o Direito moderno faça uso do Princípio da Utilidade. Cf. Harris, $2004: 43$.
} 
nada que lhe fosse natural. Eis a grande ruptura conceitual do Direito subjacente à obra de Bentham.

Como bem sumaria Harris (2004: 30), Bentham e seus seguidores implantaram a concepção de que "o soberano não era aquele que por direito natural ou divino poderia nos dizer o que deveríamos fazer. O soberano era identificado pelo fato de que ele era obedecido, e seus comandos eram aqueles que as pessoas chamam 'leis'."

Neste sentido, Bentham em muito dá seguimento aos embrionários postulados positivistas erigidos por antecessores. Ainda que os pressupostos e a abordagem sejam distinguíveis - especialmente no que se refere ao individualismo como metodologia do pensamento utilitário e à menção a um sistema natural para aqueles outros - é possível afirmar que Bentham tornou mais evidentes certos conceitos que estavam presentes, mas latentes, em autores anteriores.

Friedrich (1965: 104) chega a afirmar até mesmo o compartilhamento de fundamentos entre Bentham e predecessores como Hobbes e assevera que:

\begin{abstract}
É evidente que a Filosofia do Direito de Hobbes está quase totalmente alicerçada no princípio da utilidade. Só porque os homens acabaram por reconhecer como úteis a paz e a ordem é que se dispuseram a aceitar normas legais e a obedecer às leis.
\end{abstract}

É preciso, no entanto, reconhecer que há divergências bastante claras entre o pensamento de Hobbes e Bentham, pois somente para este último ilumina-se a contingência daquilo que se caracteriza substancialmente como Direito e só então as normas jurídicas tomam para si a qualificação de expressão da vontade livre do soberano, e deixam de ter seu fundamento natural como elemento de validade.

Mesmo nesse sentido, no que se refere ao Direito como expressão de vontade, Bentham não é exatamente original, mas tem o mérito de ter desvinculado o discurso de um viés também jusnaturalístico - além de social. "Ambos Grotius e Pufendorf se referiram ao direito humano como expressão da vontade do soberano (potestas civilis), e o mesmo o fez Hobbes." (Olivecrona, 1975: 95-96)

No entanto, ao ignorar a necessidade - tão aclamada até então - que a vontade do soberano tivesse vinculação necessária a algo racional, Bentham afastou o que havia de natural na construção do Direito e relegou a possibilidade de avaliar se as leis eram boas ou ruins apenas a partir de um viés social e, para ele, necessariamente utilitarista.

Já não eram valores imutáveis que limitavam o poder do soberano, mas sim a conveniência social de suas decisões, medidas de acordo com as conseqüências que delas resultavam ou poderiam resultar.

Em uma via mais restrita do pensamento jurídico, é interessante acrescentar que a defesa dos direitos subjetivos são convergentes tanto em Bentham como em seus predecessores como John Locke. No entanto, enquanto para os antecessores tratava-se da necessidade de que o Direito assegurasse algo que se fazia proeminente por sua origem natural, para Bentham esse fundamento naturalístico se perde e se 
estabelece a tutela estatal da propriedade como instrumento que possibilita que os indivíduos busquem sua felicidade. (Atiyah, 1995b: 150)

Em outros termos, o certo grau de liberalismo que vinha sendo suscitado antes de Bentham toma uma forma mais funcional, o que permite que esses postulados individuais prescindam dos fundamentos naturais que possuíam e se estabeleçam por suas professadas qualidades sociais.

Nessa esteira do raciocínio, o Direito esvazia-se em larga medida de sua qualificação como instrumento distributivo e a fé de que o individuo é quem melhor dá conta de seus interesses leva quase que inexoravelmente à concepção de que se preocupar com a comutação é a única função do Direito.

Incontáveis foram os autores que seguiram os postulados benthamianos, buscaram aperfeiçoá-lo ou revisitaram seus conceitos a fim de torná-los mais palatáveis. É preciso destacar alguns autores entre todos e demonstrar, ainda que sucintamente, quais suas maiores contribuições para a Escola Utilitarista.

Os ensinamentos benthamianos foram promovidos e disseminados especialmente por John Austin 4 . Em seu positivismo, Austin alçou o debate acerca da soberania a um nível de importância pouco visto até então, tomando o ente prolator da norma como fundamental para a composição de sua juridicidade. Ainda que renda tributos ao utilitarismo, suas proposições apresentam um nível bastante "purificado" do Direito, reconhecendo sua característica de vontade emanada por autoridade e em larga medida desvinculando o Direito de qualquer moral. A separação entre Direito tal como é e como deve ser - perspectivas positiva e normativa, respectivamente - torna-se ainda mais clara, sem, no entanto, desconfigurar o caráter jurídico da norma soberana que se evidencia empiricamente.

"De acordo com Austin, Direito é a ordem de um 'soberano' suportada por uma ameaça de sanção em caso de descumprimento. Uma norma é Direito, então, somente se é comando de um 'soberano'. (...) O critério de legalidade é questão de fato, não de valor." (Coleman; Leiter, 2005: 244). Essa concepção não seria possível, senão após as conquistas conceituais elaboradas por autores como Jeremy Bentham.

De um lado, isso proporcionou elementos para que se estabelecesse toda uma perspectiva formalista - de meios - com relação ao fenômeno jurídico. O que lhe importa, na definição de sua condição - já que não se pode falar em essência jurídica -é o processo segundo o qual as normas jurídicas são instituídas como determinação volitiva do Estado.

De outro lado, tomou-se possível rever o problema da materialidade do Direito, de seu conteúdo normativo.

É difundido entre os utilitaristas o entendimento da importância que tem o papel do legislador como autoridade soberana é recorrente nos discursos de Bentham e seus discípulos. Ao afastar a naturalidade do poder de comando e esvaziar a vinculação naturalística do conteúdo normativo, Jeremy e seus seguidores

${ }^{4}$ Professor de Direito na University of London nas décadas de 20 e 30 no século XIX. 
possibilitaram que houvesse o reconhecimento do verdadeiro papel da vontade do soberano na definição da substância do Direito - e, assim, na materialidade das normas. Sendo essa vontade contingente, ela pode ser melhor ou pior segundo promova ou diminua a felicidade do maior número de pessoas.

John Stuart Mill é outro grande promotor do ideário utilitarista. Ele acrescentou várias concepções que podem ser referidas como aperfeiçoamento do utilitarismo. Dentre elas, a mais debatida é a introdução da diferenciação entre prazeres menores e prazeres maiores, meio através do qual Mill responde as críticas de que o Princípio Utilitarista permite que os pequenos prazeres, notadamente os carnais, são identicamente medidos quando comparados a prazeres de elevado nível, como o gosto pelo engrandecimento cultural. ${ }^{5}$

Outro elemento reiteradamente debatido por Mill é de que há casos em que a aplicação da moral utilitarista fere o conceito intuitivo de justiça. Ele formula o raciocínio de que em tais casos não é um conceito de justiça racional que diverge do princípio utilitário, mas apenas um sentimento intelectualmente inconsistente (Crisp, 1997: 156).

Através da divulgação dos pensamentos de Jeremy Bentham ou de seus discípulos, propagou-se, por um lado, a concepção positivista que ele sem dúvidas ajudou a constituir e, por outro lado, a crença no Princípio da Utilidade como verdadeiro guia para o legislador.

Nessa última esteira, é preciso narrar que muitas reformas havidas na Inglaterra são reputadas, ainda que parcialmente, às sugestões propostas por Bentham em seus escritos ou então a autores da Escola Utilitarista que se instituiu. ${ }^{6-7}$

Em 1832, o Reform Act instituiu substanciais modernizações no Direito Inglês e os Judicature Acts de 1873 e 1875 também foram expressão de um período em que "suas idéias [de Bentham] filosóficas, jurídicas e econômicas eram dominantes." (Holdsworth, 1940 : 584)

Várias das reformas ocorridas entre 1843 e 1875 são referências a efetivação de proposições benthamianas. Podem ser listadas, entre outras, a mudança na lei de franquias ${ }^{8}$, a liberalização do comércio e a crença nas relações livres de mercado e a introdução de um sistema eficiente de cortes locais. Ainda nesse período, houve reforma sistemática no Direito Processual, reformulando os ritos a fim de simplificar os procedimentos.

Mesmo após 1875, muitas das reformas havidas são tidas como inspiradas em alguns postulados benthamianos. Dentre eles, incluem-se a minoração dos poderes da Câmara de Lordes e o aumento no grau de democracia no sistema político

${ }^{5}$ Cf. MILL, Utilitarianism In: RYAN, 1987: 272 et seq.

${ }^{6}$ As reformas legais apresentadas como influenciadas pelos pensamentos utilitaristas são indicações de Sir William Holdsworth, em seu artigo Bentham's Place in English Legal History, páginas 584 e seguintes, texto esse que consta na Bilbiografia. Sir Holdsworth foi Professor de Direito Inglês na Universidade de Oxford, em meados do século XX.

${ }^{7}$ Para mais informações sobre as reformas legislativas influenciadas por Bentham: JUDSON, 1910.

8 "Franquias", no contexto do Direito Inglês, via de regra devem ser compreendidas como as autorizações e concessões para o fornecimento privado de utilidades públicas. 
inglês e melhorias sugeridas para a configuração dos direitos de propriedade ${ }^{9}$.

Outra importante reforma que se pode notar no Direito Inglês, havida desde o século XVIII e que coaduna com os postulados defendidos pela Escola Utilitarista (Hezel, 1973), é o processo de codificação, ainda que não tenha atingido todo aquele ordenamento.

No que se refere ao Direito Penal - sem dúvida uma das maiores bandeiras de Bentham - "reformas na teoria da punição foram até além de suas sugestões." (Holdsworth, 1940: 586)

Por fim, é preciso fazer apontamentos sobre a influência dos pensamentos de Bentham na Teoria do Direito na modernidade tardia.

A corrente de pensamento que se fez conhecer por Law and Economics é uníssona ao apontar Bentham como um precursor distante, mas importante, de suas proposições.

Não é hegemônica - ao menos internamente - a concepção de que os preceitos utilitaristas foram determinantes na construção dessa teorização economicista a respeito do Direito, mas até mesmo uma análise ligeira é capaz de demonstrar as convergências entre o autor inglês do século XVIII e os autores mais relevantes da Law and Economics do século XX ${ }^{10}$.

Essa corrente contemporânea do pensamento defende a maximização, não da felicidade, mas da riqueza social agregada como valor a ser perseguido pelo Direito (Posner, 1983). A exemplo de Bentham, também usa instrumentos de análise do comportamento individual para tecer suas máximas com a finalidade de reformar (tal qual Bentham no século XVIII) e aperfeiçoar - também em termos teleológicos a construção e aplicação do Direito.

Ainda que haja variações conceituais aplicáveis, elas podem muito bem ser explicadas pelas diferenças que a disparidade temporal pode promover na apresentação do pensamento.

Sem dúvidas, o debate se tornou mais sofisticado, ganhou novos elementos e passou a reconhecer seus limites, mas em muito carrega consigo, já em meados do século XXI, as aquisições conceituais e propositivas assentadas no final do século XVIII.

\section{Conclusão}

Reconstruir e apresentar as contribuições de Jeremy Bentham na conceituação moderna do Direito é tarefa das mais complexas.

A dificuldade se dá até em razão dos meandros que o conhecimento costuma traçar e no uso de conceitos que, aparentemente utilizados de maneira bastante semelhante entre autores de épocas diferentes, trazem consigo discrepâncias

\footnotetext{
${ }^{9}$ No que se refere aos direitos de propriedade, o autor não dá elementos para que se possa perfeitamente distinguir se são tratados, no caso, os direitos que se denominam reais na Civil Law ou se, munido de conceituação possível na Common Law, a referência é a direitos subjetivos de maneira geral.

${ }^{10}$ Cf. Posner, 2004.
} 
semânticas ou vinculações a raciocínios diversos. Nessas circunstâncias, o anacronismo na consideração dos conceitos pode ensejar obstáculo quase intransponível ao levantamento histórico do conhecimento.

Mesmo em função disso, Bentham não perde sua importância na constituição do Direito positivo moderno.

O Direito vinha sendo, mesmo antes de Jeremy Bentham, diferenciado da moral e já se debatia nas academias o reconhecimento de um Direito contingente, possibilitado pela distinção entre as normas naturais e humanas.

No entanto, além de reforçar a concepção estritamente social - e, portanto, histórica - do que se pode chamar efetivamente de Direito moderno, Bentham, em seu empirismo, afasta a necessidade de tratar de um suposto Direito natural em seu âmago. Possibilita que, de um lado, o Direito seja determinado como fruto de um processo formal e, de outro, viabiliza um retorno à análise do conteúdo normativo, da materialidade do Direito, mas afastando os valores naturais como adequadas referências para a sua validação ou avaliação.

A noção de que não há uma vinculação pré-social - ou, ainda que social, de que não seja trazida pela natureza humana - possibilitou que o Utilitarismo desenvolvesse uma própria perspectiva acerca da boa legislação, traçando parâmetros relativamente objetivos e racionais para o soberano - hoje na figura do Estado -, cuja vontade é única fonte de Direito. Note-se que, ao contrário do quanto vinha sendo manifesto em sede do naturalismo jurídico, esse parâmetro não é elemento que confira a validade ao Direito, mas é tão somente capaz de qualificá-lo como benevolente ou não - por uma perspectiva não individualista, mas social.

Em face disso tudo, é interessante notar o quanto Bentham e sua Escola Utilitarista influenciaram o pensamento a respeito do Direito em toda a Modemidade, estabelecendo conceitos e paradigmas de abordagem que, promovidos, criticados e revisitados, estimularam uma modalidade toda própria de reflexão acerca do Direito na Modernidade.

Ademais, é relevante ainda destacar que esse paradigma, ora retomado em sua completude -inclusive em seu aspecto filosófico - é tomado como base moral de uma nova corrente de análise do Direito contemporâneo. De certo, o pensamento de Jeremy Bentham, muito além de ter cooperado na elaboração do conceito positivista do Direito Moderno, ainda há de influenciar os teóricos do Direito na constante evolução dos conceitos acerca do fenômeno jurídico.

\section{Bibliografia}

ATIYAH, P. S. An introduction to the law of contract. 5th. ed. New York: Oxford University Press, 1995.

Law and Modern Society. 2nd. ed. New York: Oxford University Press, 1995b. 
BENTHAM, Jeremy. Uma Introdução aos Princípios da Moral e da Legislação. São Paulo: Abril, 1979. (Os Pensadores).

COLEMAN, Jules. MURPHY, Jeffrie. Philosophy of Law: an introduction to Jurisprudence.. Revised ed. sine loco: Westview, 1990. . LEITER, Brian. Legal positivism. In: PATTERSON, Dennis (ed.). A Companion to Philosophy and Leal Theory. Malden: Blackwell, 2005.

CRISP, Roger. Mill on Utilitarianism. New York: Routledge, 1997.

FRIEDRICH, Carl Joachin. Perspectiva histórica da filosofia do Direito. Rio de Janeiro: Zahar, 1965.

HART, H. L. Bentham and the demystification of the Law. In: Modern Law Review. Vol. 36. 1973.

HARRIS, J. W. Legal philosophies. 2nd. ed. Oxfor: Oxford University Press, 2004.

HEZEL, George. The influence of Bentham's philosophy of law on the early nineteenth century codification movement in the United States. In Buffalo Law Review. 1972-1973.

HOLDSWORTH, William. Bentham's place in English Legal History. In: California Law Review. Vol. 28. 1939-1940. p. 568-586.

KELLY, John Maurice. A short history of western legal theory. Oxford: Clarendon, 1994. KOLM, Serge-Christophe. Modern Theoris of Justice. Cambridge: MIT, 1996.

JUDSON, Frederick. A modern view of the law reforms of Jeremy Bentham. In: Columbia Law Review. Vol. 41. 1910.

LOPES, José Reinaldo de Lima. As palavras e a lei: Direito, Ordem e Justiça na História do Pensamento Jurídico Moderno. São Paulo: Editora 34, 2004.

MAJUMDAR, Tapas. The measurement of utility. 3rd. ed. London: MacMillan, 1966.

NEWMAN, Peter (ed.). The new Palgrave Dictionary of Economics and the Law. Vol. 1. New York: Palgrave MacMillan, 2002. p. 156-164.

OLIVECRONA, Karl. The will of the sovereign: some reflections on Bentham's concept of 'a Law'. In: The american Journal of Jurisprudence. Vol. 95. 1975.

PAGE, Alfred N. Utility theory: a book of readings. New York: Joh Wiley \& Sons, 1968. POSNER, Richard. Conceptions of Legal "Theory": a response to Ronald Dworkin. Arizona State Law Journal. No ${ }^{\circ}$ 29. P. 377-388. 1997.

. Frontiers of legal theory. Cambridge: Harvard University Press, 2004.

The economics of Justice. [2nd. ed.]. Cambridge: Havard University Press, 1983. 
The ethical and political basis of the efficiency norm in Common Law adjudication. Hofstra Law Review. Vol. 8, 1979-1980. p. 487-507.

. The problematics of Moral and Legal Theory. $3^{a}$. impressão. Cambridge: Harvard University Press, 2002.

The problems of Jurisprudence. Cambridge: Harvard University Press, 1990.

ROBERTSON, Dennis. Utility and all that and othe essays. 2nd. impression. Norwich: Jarrold and Sons, 1954.

RYAN, Alan (ed.). Utilitarianism and other essays. New York: Penguin Books, 1987.

SEN, Amartya. WILLIAMS, Bernard. Utilitarianism and beyond. 4th. ed. Cambridge: Cambridge University Press, 1988.

SHAVELL, Steven. Foundations of Economic Analysis of Law. Cambridge: Harvard, 2004. 